
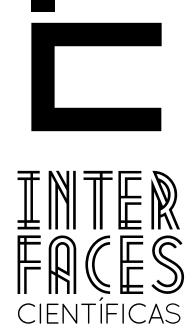

DIREITO

\title{
DIREITO, HISTÓRIA E LTTERATURA: REFLEXÕES EPISTEMOLÓGICAS A PARTIR DA OBRA DE JOÃO GUMES
}

Roberto Henrique Pôrto Nogueira ${ }^{1}$
Maria Lúcia Pôrto Silva Nogueira²

\section{RESUMO}

0 presente trabalho tem por objetivo apresentar algumas reflexões sobre as possibilidades de diálogo entre o Direito, História, Literatura, passando por considerações sobre os conceitos de cultura, língua, linguagem e literatura, para se chegar à discussão dos caminhos metodológicos possíveis numa abordagem deste tipo. Considerando que as produções literárias (por ora especialmente os romances) podem constituir-se em fontes históricas de grande potencial para o estudo de um contexto jurídico-social de uma determinada época, são apresentados aqui pontos de vista de vários autores que elucidam a questão e apontam para um fértil "dialogismo" entre esses campos de conhecimento. Preservadas as especificidades de tais fontes, é possível realizar um trabalho historiográfico sério e comprometido com o rigor metodológico. 0 teste das hipóteses acontece por breve análise da obra de João Gumes, no Alto Sertão Baiano do início do Século XX.

\section{PALAVRAS-CHAVE}

Direito. Literatura. Fontes Históricas. Dialogismo. Princípios. 


\section{ABSTRACT}

This paper has the objective to show some reflections on the possibilities of the dialogue between Law, History and Literature, and show some considerations about the concepts of culture, language and literature, in order to discuss the possible methodological ways of this type of approach. Considering that the literary productions (specially the novels) can be historical sources with great potential to the study of a specific social and juridical context, points of view are presented here from various authors that elucidate this problem and point to a fertile "dialogism" between these knowledge areas. Since the characteristics of such sources are preserved, it is possible to succeed in a serious historiographical work engaged with the methodological accuracy. The hypotheses were tested through a succinct analysis of João Gumes' literature, in Alto Sertão Baiano, Brazil, in early twentieth century.

\section{KEYWORDS}

Law. Literature. Historical Sources. Dialogism. Principles.

\section{CONSIDERAÇ̃̃ES INICIAIS}

A discussão da inter-relação Direito, História e Literatura pode seguir uma infinidade de vieses. Explorar, em forma de ensaio, o manancial que esta aproximação representa para a pesquisa histórico-jurídica é o objetivo do presente trabalho. As reflexões feitas aqui buscam evidenciar quão profícuas e enriquecedoras podem mostrar-se as produções literárias no ofício do pesquisador, ainda que este caminho se mostre cheio de polêmicas e de posturas antagônicas no mundo acadêmico.

\section{RESUMEN}

Este trabajo tiene como objetivo presentar algunas reflexiones sobre las posibilidades de diálogo entre el derecho, la historia, la literatura, a través de la consideración de los conceptos de cultura, idioma, lengua y literatura, para llegar a la discusión de los posibles enfoques metodológicos para este tipo de enfoque. Considerando que las producciones literarias (por ahora sobre todo novelas), pueden constituirse en una fuente de gran potencial para el estudio histórico de un contexto socio-jurídica de un momento dado, se presentan puntos de vista de varios autores que dilucidar la cuestión y apuntan a un fértil "dialogismo" entre estos campos del conocimiento. Conservadas las características específicas de estas fuentes, se puede realizar un trabajo historiográfico serio y comprometido con el rigor metodológico. La prueba de las hipótesis se da por el breve análisis de la obra de John Gumes en el alto desierto bahiano en principios del siglo XX.

\section{PALABRAS CLAVE}

Derecho. Literatura. Fuentes Históricas. Dialogismo. Principios.
Se a conclusão for positiva, para validar a Literatura como recurso viável à pesquisa histórica, terão lugar algumas reflexões sobre a possibilidade de se inferir, exclusivamente sobre o fato histórico aferível na Literatura, algum aspecto útil ao Direito. Esta parte da empreitada é encarada sem a pretensão de estudos legais ou doutrinários, mas partirá, para o teste da hipótese, para uma abordagem exclusivamente histórico-literária.

Vale explicar que: tomando por base a obra de João Gumes, a qual será adiante apresentada, buscar- 
-se-á anunciar alguma característica das obrigações associativas intersubjetivamente reconhecidas, aptas a preencherem o conteúdo deôntico de princípios jurídicos.

Como o trabalho é, prevalentemente, metacientífico, a exploração da relação dos fatos com as obrigações associativas e, por fim, dessas com os princípios jurídicos será tratada no decorrer do texto.

Não se busca aqui, definir princípios, mas, apenas identificar clamores e tendências de obrigações associativas que existem em determinado contexto, sinali-

\section{PRESSUPOSTOS TEÓRICOS ACERCA DA CON- CEPÇÃO DOS PRINCÍPIOS JURÍDICOS}

Para que seja apresentado um determinado panorama jurídico de uma comunidade personificada, de onde se evidenciam os princípios que fundamentam a concepção interpretativa preconizada por Ronald Dworkin, é imprescindível o entendimento dessa comunidade, pressuposta pela integridade política. Tal comunidade, por certo, depende de um contexto temporal e espacial para definir-se.

Tal personificação é entendida por Dwokin (2003, p. 204) como sendo uma maneira especial de formação de uma entidade, que não se confunde com as pessoas ou cidadãos que a compõem.

Dworkin (2003, p. 208) consegue identificar a comunidade como um agente moral. Nesse sentido, é capaz de engendrar princípios próprios, passíveis de serem observados ou desconsiderados por essa comunidade, dotada de consciência transcendente aos seus membros, que a reconhecendo ou não como convergente com a consciência individual, admitem sua validade e extensão. A comunidade personificada, zando o que viria a preencher o conteúdo deôntico dos princípios que dada arquitetura anuncia. Voltamo-nos aos anúncios de transformação jurídico-social.

Validados os métodos, o presente estudo poderá servir de pressuposto teórico à fase futura da pesquisa, que aprofundará a investigação do fato histórico a partir da Literatura, com fincas à construção hermenêutica dos contornos, não somente semânticos, mas, sobretudo, jurídicos, de princípios também jurídicos vigentes em uma época, numa determinada comunidade.

portanto, também possui seus próprios princípios ou convicções, que não necessariamente coincidem com as de seus membros.

A personificação, assim, visa à atribuição de condutas, intenções e convicções ao ente, sem a tradução redutiva da simples representatividade das individualidades. Utilizando o exemplo da atribuição de responsabilidade ao ente, pontua-se que os indivíduos não necessariamente participam da cadeia causal para fins de configuração dessa responsabilidade, não aparentando, pois, correto que estes, ainda que indiretamente, sejam responsabilizados. Isso porque, eventual erro, provavelmente, não poderá ter sua autoria ligada a alguém específico e isoladamente. Desse modo, é considerável a responsabilidade da instituição corporificada como um todo, o que prescinde da avaliação da conduta, intenção ou convicção de cada indivíduo.

Acredita-se que a personificação é dotada de evidente caráter intersubjetivo, pois a consciência co- 
munitária, apesar de depender do reconhecimento individual, em nada corresponde à moral privada. 0 delineamento da comunidade personificada depende, antes, do compartilhamento do mínimo de consenso sobre conceitos centrais, em torno dos quais se fundam seus princípios, em especial, das construções comunitárias da justiça política e equidade. Dworkin explica:

\begin{abstract}
Portanto, não podemos explicar as responsabilidades especiais da função política se tentarmos extraí-las diretamente de princípios correntes da moralidade privada. Precisamos de uma idéia que não se encontra ali: a de que a comunidade como um todo tem obrigações de imparcialidade para com seus membros, e que as autoridades se comportam como agentes da comunidade ao exercerem essa responsabilidade. (DWORKIN, 2003, p. 212).
\end{abstract}

Assim, há de se questionar qual é o fator de coesão, viabilizador da personificação. Trata-se, esse fator, de um ideal político, que teria sido pelo menos almejado pela retórica revolucionária francesa. Aqui, nenhuma síntese seria fiel às palavras de Dworkin (2003, p. 228): “A retórica revolucionária [reconheceu um ideal político:] Deveríamos procurar nossa defesa da integridade nas imediações da fraternidade, ou, para usar seu nome mais difundido, da comunidade”.

O fator de coesão, a reciprocidade, é coincidente ao fundamento da obrigação comunitária ou associativa. A legitimidade dessa obrigação implica o tracejo dos lindes da comunidade.

A reciprocidade, todavia, é conceito interpretativo (DWORKIN, 2003, p. 240), e é exatamente o compartilhamento, entre determinados membros, da concepção da reciprocidade, que define a extensão da obrigação comunitária e, por conseguinte, da própria comunidade.

Se a comunidade personificada pode ser delineada, deve poder agir legitimamente. E, para Dworkin (2003), poderá agir legitimamente se a comunidade for verdadeira, ou seja, caso constitua, efetivamente, o que ele trata como comunidade básica.
Cabe explicar. A abordagem dworkiniana parte da obrigação política, que se genuína, assegura a autoridade moral do Estado. Porém, diante da afirmação do papel desempenhado pela obrigação política na integridade política da comunidade, uma nova questão impõe-se, qual seja aquela sobre o fundamento dessa obrigação política.

A lição de Dworkin (2003, p. 232) é no sentido de que os instrumentos normativos aprovados pelo legislativo não são o fundamento da obrigação política, porque mesmo aqueles que desrespeitam tais instrumentos normativos, validam a legitimidade da coerção oficial e, consequentemente, a autoridade moral do Estado.

Dworkin (2003, p. 233) também rejeita a ideia de que a legitimidade da autoridade estatal estaria relacionada à ideia de um acordo tácito firmado entre Estado e membros, pois esse acordo não poderia ser estendido a todos. Refuta, ainda, a visão de John Rawls, de que a obrigação política se legitimaria a partir de um dever de apoiar as instituições minimamente justas, pois permaneceria sem explicação a relação entre a obrigação política reconhecida pelos membros e a comunidade específica, a relação entre a variável concepção de justiça de determinada comunidade e a respectiva obrigação (DWORKIN, 2003, p. 234).

Por fim, Dworkin (2003) ataca a teoria do jogo limpo, que afirma que os indivíduos de uma comunidade, beneficiados de alguma forma por sua organização política, aceitariam, automaticamente, suas obrigações internas, ainda que jamais tivessem buscado tais benefícios. A crítica a essa noção de jogo limpo baseia-se no entendimento de que o reconhecimento das obrigações não é automático, tampouco é possível a exigibilidade obrigacional em circunstâncias de inocorrência de efetivo aumento de bem-estar do indivíduo.

As pessoas não reconhecem obrigações como sendo legítimas em uma comunidade pelo simples fato de pertencerem a ela, pois, ainda assim, por 
não poderem escolher integrá-la ou não, podem não reconhecer as obrigações comunitárias. Não dependem de laços emocionais, tampouco correspondem a grandes paixões, tais como nacionalismo ou racismo (DWORKIN, 2003, p. 238).

Destarte, Dworkin (2003, p. 239) entende que as obrigações associativas ou comunitárias são legítimas por outras razões: as obrigações são atraídas por uma história de eventos difusos e escolhas que, individualmente, são imperceptíveis. Significa que tais obrigações existem no contexto da intersubjetividade, pressupondo, assim, a reciprocidade, que é compreendida como compartilhamento de uma ideia geral e difusa dos direitos e das responsabilidades (DWORKIN, 2003, p. 241). Os limites da personificação relacionam-se intimamente com o compartilhamento no reconhecimento das obrigações associativas.

Para o teórico, o Direito é associado à possibilidade da justificativa da coerção oficial, e, em especial, de seu monopólio por parte da comunidade. Surge a tarefa de demonstrar qual concepção interpretativa é capaz de justificar o monopólio da coerção oficial. Isso porque, a comunidade básica deve engendrar responsabilidades genuínas, e essa última característica está ligada à atitude interpretativa. Assegurada a genuinidade, terá sido demonstrado que a obrigação política é associativa.

Para o teórico, o modelo seria o da comunidade de princípios, pelo qual cada um aceita a integridade política, decorrente do fato histórico da adoção de um sistema de princípios. Mesmo numa sociedade moralmente plural, a personificação é possível, porque a especialização e identificação das obrigações acontecem para cada um e para todos os seus membros, que se interessam pelo bem da comunidade e são igualmente considerados por ela.

Isto pode significar que a comunidade pode ser tida como uma criação das práticas de pensamento e linguagem nas quais se inscreve (DWORKIN, 2003, p. 208). Logo, as tais obrigações que fundamentam a coercibilidade dos princípios jurídicos podem depender da investigação, posterior atitude interpretativa e das práticas sociais e políticas de pensamento e linguagem nas quais se inscreve.

Se isso procede, vale o recurso à pesquisa histórica, em busca de fatos que evidenciam obrigações associativas que, por sua vez, fundamentam e dão azo aos princípios jurídicos de um dado contexto. Resta saber se a Literatura é firme como fonte dessa investigação histórico-jurídica.

\section{HISTÓRIA E LITERATURA: ALGUMAS REFLE- XÕES EPISTEMOLÓGICAS}

É sabido que a partir da década de 1970, com as propostas trazidas pela Nova História, a noção de documento histórico se alargou consideravelmente, deslocando pontos de interesse em várias direções, em novos enfoques. Movimento este que incorporou não só as fontes literárias, mas um número sem fim de outras fontes para a pesquisa histórica ${ }^{1}$.

Uma onda crescente de estudos com novas abordagens historiográficas é visível no âmbito da História

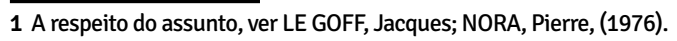


da Cultura. Vale considerar, principalmente no foco de interesse deste trabalho, a relevância dos aspectos culturais nas análises das relações sociais e até mesmo jurídicas, o que passa a ser uma atitude profícua em determinadas correntes de pensamento que trazem reflexões sobre a cultura, melhor dizendo, culturas, considerando-as como evidências materiais, concretas, reais, no mesmo conjunto com outras eivadas de sensibilidade que expressem crenças e valores e em que subjetividades possam aflorar na dinâmica do social e dar a perceber identidades. São subjetividades que carregam em si a experiência do vivido e, portanto, traduzem as informações do seu mundo real, constituindo os saberes locais, linguagens locais, tão necessários hoje em contraposição a um mundo que se quer global (WILLIAMS, 1979).

Nesse sentido, vale considerar ainda que, no revisionismo dos estudos marxistas, a cultura não pode mais ser vista como superestrutura; este conceito foi repensado, buscando apontar caminhos possíveis de identificação, incorporação e compreensão de identidades que se multiplicam incessantemente no bojo das transformações sócio- econômicas do mundo contemporâneo.

Para se chegar ao conceito de Literatura como se quer neste trabalho, vale analisar a importância da língua enquanto meio de comunicação e relacionamento entre os grupos sociais e o seu reflexo na constituição da linguagem. Nesse sentido, Williams (1979) analisa o peso que tem a língua falada em determinado local e que, ao criar um conceito, já o faz carregado de cultura; a língua produz redes de conhecimento da realidade e se faz presente no processo de organização daquela sociedade. Ela se torna um mecanismo de poder cada vez mais eficiente a partir das facilidades trazidas pela técnica - imprensa e outros meios de comunicação. Assim diz este autor: " $A$ linguagem deve ser vista então como um tipo persistente de criação e recriação: uma presença dinâmica e um processo regenerativo constante" (WILLIAMS, 1979, p. 37). Os variados e complexos usos práticos da linguagem incluem à Literatura um conceito que, visto numa acepção atualizada, pode se constituir em fonte histórica, desde que resguardadas as suas especificidades.

A Literatura é um dos meios que pode revelar aquilo que está mudando numa sociedade, mas que ainda não se instalou de forma consciente e "por vezes não está nem mesmo chegando", mas é algo que "está sendo realmente vivido". Como não se pode reduzir o social a formas fixas, é preciso considerar que as mudanças sociais resultam de mudanças nas "estruturas de sentimento"; as estruturas de sentimento representam assim, processos vivos experimentados na urdidura de confronto das diferentes classes sociais, representam transitoriamente este algo que muda, este algo obscuro, ainda bastante geral que poderia ser chamado de "estilo" e que aparece nos comportamentos sociais, indício de mudanças na sociedade. São sinais que vão tomando forma e se circunscrevendo a determinados grupos, ainda que carregados de tensões (WILLIAMS, 1979, p. 132-134).

Para mostrar a importância desses processos, Thompson (1981) analisa em $A$ miséria da teoria, a noção de "experiência" como o "termo ausente" na teoria marxista; como aquilo que se tornou uma armadilha para os que ficaram presos à trama do capital e o que expulsam de suas análises "sob injúrias... e com o nome de empirismo". Na sua análise, refere-se aos "conceitos de junção", entre eles o de "necessidade" como o que expressa a "norma" na Antropologia ou as "vontades" e os "valores" na História; o conceito de "modo de produção", segundo ele, engessou toda a cultura, toda a vida social, toda a "experiência humana”. A contribuição de Thompson neste sentido se dá quando ele procura articular os citados "conceitos de junção" às noções de "experiência" e de cultura:

[...] as pessoas não experimentam sua própria experiência apenas como idéias, no âmbito do pensamento e de seus procedimentos... elas também experimentam sua experiência como sentimento e lidam com esses sentimentos na cultura, como normas, obri- 
gações familiares e de parentesco, e reciprocidades, como valores ou (através de formas mais elaboradas) na arte ou nas convicções religiosas. Essa metade da cultura (e é uma metade completa) pode ser descrita como consciência afetiva e moral. (THOMPSON, 1981, p. 181-182)

Para Bakhtin (1992, p. 362-366), a Literatura deve caminhar ao lado da História da Cultura numa vinculação bem estreita, assim como uma "parte inalienável da cultura”, pois só assim é possível compreendê-la. Inquirido sobre a viabilidade dos estudos literários em processo, responde afirmando que, felizmente, todos os bons trabalhos literários dos últimos anos buscam garantir a junção literatura - cultura e assim compreender o fato literário "dentro da totalidade da cultura de uma época”. Afirma que, desde o início da sua longa existência, este gênero "acumula as formas de uma visão do mundo e de um pensamento". Nem sempre a criação literária é compreendida e aproveitada em toda a sua plenitude pelos seus contemporâneos ou mesmo pelo autor; este é "um prisioneiro da sua época", mas "os tempos que the sucedem o libertam dessa prisão e a ciência literária tem a vocação de contribuir para esta libertação".

Entre os gêneros literários, o romance ocupa um lugar central na obra de Bakhtin que o considera plurilinguístico, pluriestilístico e plurivocal. Como nos diz Fiorin ao discutir as ideias bakhtinianas, ele é "a expressão do dialogismo no seu mais alto grau, dando um lugar mais destacado do que os outros gêneros à diversidade, à diferença, à heterologia". Nesta perspectiva, o romance é analisado a partir da percepção da linguagem e da representação do espaço e do tempo. Ele nos permite conhecer o mundo natural e o mundo da língua, "em sua realidade heterogênea, dialógica, plural”. Além de ter uma linguagem própria, "ele opera com o dialogismo discursivo de cada momento de uma dada formação social” (FIORIN, 2008, p. 115-139).

Para falar da origem do romance, Bakhtin afirma a sua existência desde os primórdios da sociedade ocidental na Grécia Antiga, enquanto Lukács (1999, p. 102), numa posição oposta, classifica-o como uma "epopéia burguesa" que surgiu da luta ideológica da burguesia contra o feudalismo; entretanto, uma contribuição deste último, foi apontar que o romance passou a representar cada vez mais a realidade cotidiana da vida privada do burguês e as contradições do processo histórico e social. Walter Benjamim, um dos seus seguidores, enfatiza que já nos poemas homéricos, estava anunciada a "memória perpetuadora do romancista" e explicando melhor nos diz que, "a rememoração, musa do romance, surge ao lado da memória, musa da narrativa, depois que a desagregação da poesia épica apagou a unidade de sua origem comum na reminiscência”. E cita Lukács para quem o romance,

[...] somente o romance....separa o sentido e a vida e, portanto, o essencial e o temporal; podemos quase dizer que toda a ação interna do romance não é senão a luta contra o poder do tempo...Desse combate... emergem as experiências temporais autenticamente épicas: a esperança e a reminiscência...Somente no romance... ocorre uma reminiscência criadora, que atinge o seu objeto e o transforma...(BENJAMIN, 1994, p. 211-212).

A ideia de valorização do romance é também defendida por Roger Chartier (2009, p. 25-42), quando diz que "algumas obras literárias moldaram as representações coletivas do passado mais poderosamente que os escritos de historiadores"; apresenta como exemplo para isso o romance do século XIX, atribuindo-lhe uma força capaz de 'produzir, moldar e organizar' as vivências de um grupo e que o faz quando se apodera do passado, registra fatos e personagens colocados como reais e que, finalmente, são apreendidos e incorporados como senso comum. E acrescenta mais, que "os processos que conferem existência ao escrito em suas diversas formas, públicas ou privadas, efêmeras ou duradouras, também se convertem no próprio material da invenção literária”.

Cabe lembrar aqui, as tendências historicistas de interpretação que, eivadas de relativismo, veem na 
literatura os registros diretos de fatos e aspectos do meio e da época, concluindo "que cada país e cada povo possui, necessariamente, a sua própria, com características peculiares", conforme preleciona Antonio Candido (2008, p. 178).

No Brasil, a literatura assume um papel sui generis no momento em que as noções de brasilidade são debatidas e divulgadas a partir de manifestações literárias. É, ainda, o que o mesmo afirma:

a literatura contribuiu com eficácia maior do que se supõe para formar uma consciência nacional e pesquisar a vida e os problemas dos brasileiros. Pois ela fo menos um empecilho à formação do espírito científico e técnico (sem condições para desenvolver-se) do que um paliativo a sua fraqueza. Basta refletir sobre 0 papel importantíssimo do romance oitocentista como exploração e revelação do Brasil aos brasileiros (CANDIDO, 2008, p. 139-140)

Muito forte se fez esta contribuição no bojo das discussões, angústias e contradições em busca de uma identidade nacional na virada do século XIX para o século XX, momento importante no estudo do imaginário sobre a população brasileira e da busca de explicações e definições de uma identidade pautada em padrões de uma cultura ocidental e que se pretendia global; neste momento, as representações literárias de escritores clássicos brasileiros, a exemplo de Monteiro Lobato, levaram à construção de um estereótipo de "brasileiro" marcado por qualidades negativas, tais como "atrasado", "caipira" ou mesmo "indolente" e "preguiçoso" como o personagem Jeca Tatu (NAXARA, 1998, p. 19).

Entretanto, é importante não perder de vista um dado fundamental, que é o limite de fronteiras entre os dois campos, o da História e o da Literatura, preservando-se as especificidades de cada um, conforme já foi dito anteriormente. Ao ofício do historiador e ao do escritor cabem as respectivas singularidades: ao primeiro cabe ocupar-se da realidade, enquanto o segundo se relaciona ao campo daquilo que é verossímil. 0 compromisso do historiador prende-se a uma explicação da realidade, pautada numa verdade ou, no mínimo, a máxima aproximação possível da mesma. Por outro lado, afirma Nicolau Sevcenko (1999, p. 23), que se literatura se prende ao campo das possibilidades, “dos planos que não se concretizaram”, isso dá margem a uma produção historiográfica que incorpora o grupo dos vencidos, dos "que ficaram marginais ao sucesso dos fatos". Desta forma, torna-se um recurso privilegiado para a "elucidação quer das tensões históricas cruciais de um período, quer dos seus dilemas culturais".

Resguardadas as características estéticas implícitas nas obras literárias, é possível considerá-las num conjunto de significados articulados a uma dimensão social; sem dúvida, o escritor acaba por traduzir a sociedade em que vive, inscrevendo-se como testemunho e revelando pontos de tensões, denúncias ou anúncios de seu tempo, como bem ilustra Sevcenko:

\begin{abstract}
[...] todo escritor possui uma espécie de liberdade condicional de criação, uma vez que os seus temas, motivos, valores, normas ou revoltas são fornecidos ou sugeridos pela sua sociedade e seu tempo - e é destes que eles falam. Fora de qualquer dúvida: a literatura é antes de mais nada um produto artístico, destinado a agradar e a comover; mas como se pode imaginar uma árvore sem raízes, ou como pode a qualidade dos seus frutos não depender das características do solo, da natureza do clima e das condições ambientais? (SEVCENKO, 1999, p. 20).
\end{abstract}

Opiniões sobre o trabalho do historiador neste mesmo sentido foram apresentadas por Walter Benjamim (1994, p. 229-230), para enfatizar a necessidade de o historiador estar atento para lidar com os rastros, sinais e evidências, "ver o relampejar" como forma de detectar aquilo que é importante para realizar o seu ofício, um trabalho que envolve decisão e ação política. Para isso, é necessário fazer a "história a contrapelo”, abrindo mão dos discursos letrados e indo atrás de narrativas carregadas de memória, de experiências que desvelam sensibilidades e subjetividades.

Diante de todas estas evidências da estreita relação da História com a Literatura, cabe ainda refletir 
sobre as dificuldades na forma escolhida para trilhar este caminho na pesquisa histórica. Que método ou metodologia adotar? Segundo Bakhtin (1992, p. 364), ao se fazer uso da ciência literária (mesmo no processo da pesquisa histórica), deve-se considerar a sua complexidade e o fato da mesma encontrar-se num estágio considerado jovem e assim, não se pode eleger ou priorizar uma metodologia qualquer como se fosse "um remédio milagroso"; justifica-se uma diversidade de procedimentos desde que os mesmos estejam comprometidos com a seriedade e com o interesse em buscar fundos aspectos que contribuam para uma maior compreensão do que se quer elucidar.

Para Antonio Candido (2008, p. 177-199), uma metodologia que queira analisar a função histórica ou social de uma obra deve prender-se a sua estrutura literária, de modo a "buscar a organização formal de certas representações mentais, condicionadas pela sociedade em que a obra foi escrita"; prender-se a um nível do que é real e a outro de elaboração linguística desta realidade; considerar a "diferença de perspectiva dos contemporâneos da obra, inclusive do próprio autor" e até do que representa no distanciamento do tempo, pois assim é possível ver "as variações históricas de função numa estrutura que permanece esteticamente invariável". É assim que se circunscreve o destino da obra no tempo e atenua o hiato frequentemente existente entre a investigação histórica e a singularidade estética das obras literárias.

Nesse enfoque, é mister reafirmar o lugar das produções literárias no trabalho historiográfico daqueles que as tomam como fontes históricas e que vão utilizá-las como "representações" de uma época e elucidação de uma dada leitura da realidade. Estudar "as representações" significa incluir modos de pensar e de sentir, não só da coletividade, mas, como diz Jacques Le Goff (1994, p. 11), englobar "todas e quaisquer traduções mentais de uma realidade exterior percebida".

Identificar como em diferentes momentos e lugares "cada realidade social é construída, pensada, dada a ler" é um ponto importante do pensamento de Roger Chartier. Para ele, essas representações não se fazem de forma neutra ou ingênua; estão sempre colocadas de forma a refletir as competições e disputas pelo poder. Portanto, "as lutas de representações têm tanta importância como as lutas econômicas para compreender os mecanismos pelos quais um grupo impõe, ou tenta impor, a sua concepção do mundo social, os valores que são os seus, e o seu domínio" (CHARTIER, 1988, p. 17).

Outra discussão metodológica muito presente entre os que se interessam pela abordagem feita aqui, é de como fugir das armadilhas da falsificação da História e garantir o compromisso com a "verdade histórica”. Neste particular, existem procedimentos e posturas que se revelam confiáveis no tratamento com as fontes de todo trabalho historiográfico. No caso específico das fontes literárias, em sendo consideradas como testemunhos históricos, devem ser dessacralizadas e submetidas a um interrogatório sistemático. (CHALHOUB, 1998, p. 7).

Ao historiador é permitida a análise interna das obras, conforme nos diz Ferreira, mas o seu objetivo não deve ser o mesmo da crítica literária e da teoria estética, que muitas vezes se restringem à lógica dos textos. E continua dizendo que, de todas as possibilidades existentes, nenhuma pode ser reproduzida como modelo: o método será sempre construído pelo pesquisador no contato com seu objeto. Em face do cipoal de teorias hoje existentes, o que deve prevalecer é o bom senso. (FERREIRA, 2009, p. 81-82).

Importante e imprescindível para o historiador, uma vez que precisa compreender as fontes em seus contextos históricos e sociais, é confrontar as suas fontes com outros muitos e variados documentos referentes ao recorte temporal do seu objeto de pesquisa. Numa investigação de caráter qualitativo, é possível estabelecer relações dialógicas entre as mesmas, para se chegar a um aprofundamento para além do conteúdo manifesto (RICHARDSON, 1999, p. 103). 
Nesta perspectiva, um enfoque dialético ganha importância na medida em que aponta contradições possíveis entre os aspectos que se pretende correlacionar e isso possibilita a apreensão de uma realidade mais ampla, cobrindo as limitações de construções puramente subjetivas.

Ao analisar aspectos do método na história cultural, Burke (2005, p. 34) aponta uma alternativa conhecida como "análise de conteúdo", muito utilizada nas faculdades norte-americanas no início do século $\mathrm{XX}$, quando os jornalistas queriam obter informações confiáveis sobre as notícias e ações dos alemães durante a guerra. Este procedimento quando associado à argumentação, usada na "análise de discurso", traz maior aproximação do universo de representações subjetivas.

Com este conjunto de técnicas, Bardin (1977, p. 42) aponta a viabilidade de, não só se "compreender o sentido da comunicação (como se fosse o receptor normal), mas, também e principalmente, desviar o olhar para outra mensagem entrevista através ou ao lado da mensagem primeira”.

Numa tarefa inicial, e definida a análise por tema, buscar-se-á estabelecer as unidades de registro que podem ser palavras, expressões ou enunciados, numa relação com outros que the darão sentido ou de acordo com a posição que ocupam no conteúdo.

Pretende-se, com este modelo, fazer inferências numa análise relacional entre unidades de registro e unidades de contexto. Isto pode ser apontado como o que diferencia a análise de conteúdo de uma análise documental: a primeira trabalha mensagens descobrindo indicadores que the permitam inferir sobre uma outra realidade e não apenas classificar e condensar informações sobre determinado material como faz a segunda (BARDIN, 1977, p. 41).

Para concluir essas reflexões, cumpre lembrar a indagação feita por Ferreira (2009, p. 84-85): "que outras fontes a não ser as artísticas, dentre as quais sobressai a literatura, deixariam registros tão preciosos e plurissignificativos desse universo humano recôndito, frequentemente recalcado noutros documentos?". Desta forma, só resta aos historiadores, lançarem mão do texto literário, essa fonte fecunda dos desejos que, inundando a materialidade das coisas, também constituem a história.

Enfim, caminhar nesta perspectiva inclui uma audácia que não está isenta de riscos, mas cuja responsabilidade cabe inteiramente à decisão do pesquisador que acredita ser possível atingir o seu objeto de estudo por outras vias e com maior profundidade.

\section{ESCRITOR E O RETRATO DE SEU TEMPO}

Para articular História e Literatura à pesquisa jurídica, interessa ao estudo apresentar o retrato do contexto cultural no qual se insere o escritor. João Antônio dos Santos Gumes (1858-1930), escritor que anunciou o Alto Sertão baiano ${ }^{2}$ em todas as suas singularidades cultu-

2 Segundo Neves (1998, p. 22), “geralmente definem região de modo pouco preciso física ou sócio-economicamente, como área que se pretende delimitar, com 'critérios parciais da espacialidade, que 'recortam a base física': região semi-árida, demarcada pelos fenômenos climáticos; região do sertão caracterizada pela morfologia da vegetação; região do Alto Sertão da Bahia, referenciada na posição relativa ao curso do rio São Francisco na Bahia e ao

rais, registrou os seus problemas em busca de soluções e traduziu concepções intersubjetivas da época. Jornalista e literato, produziu vários trabalhos, alguns inéditos, cujo acervo é encontrado no Arquivo Público Municipal

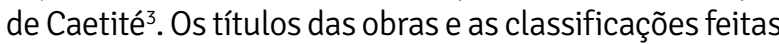

relevo baiano que ali projeta as maiores altitudes".

3 Cidade natal de João Gumes, de onde ele nunca se ausentou; está localizada no Sudoeste da Bahia, a $757 \mathrm{~km}$ da capital. No início do século XX, desfrutava posição privilegiada em assuntos políticos e econômicos e como centro difusor de cultura pelo seu progresso no setor educacional. 
pelo autor, tais como "romance de costumes sertanejos" ou "romance de folk-lorismo" ou ainda "romance moralizador e philosofico" entre outros, só aumentaram o interesse por essas leituras.

Como jornalista, utilizava-se das crônicas para fazer a escrita do seu tempo, e no Jornal $A$ Penna $a^{4}$ publicava os assuntos que mais o inquietavam, a exemplo da grande seca de 1899, em que as suas crônicas em série traziam títulos como "Alarma", "Horror", "Desespero", "Êxodo". Isso demonstrava a sua preocupação com as causas sociais e com os efeitos do flagelo da seca na vida do sertanejo; demonstrava a sua insistente luta em favor dos menos favorecidos e em defesa de políticas públicas que pudessem trazer assistência aos mais pobres e desvalidos e melhorar as suas condições de vida. Neste gênero, escreveu como quem "possui certas habilidades literárias e assume uma determinada postura diante da vida", como quem possui "humor, capacidade analítica, concisão, leveza, compromisso com o leitor" (DANNER, 2005, p. 272).

Para Gumes, a literatura era tida como uma segunda ocupação, não sendo, portanto, o seu meio de ganhar a vida; dedicou-se à atividade romanesca mais na sua maturidade, em virtude de estar antes envolvido com as atribuições no serviço público e de jornalista.

Como viés para entender a época em que as ideias de Gumes estavam sendo gestadas, vale considerar que havia a consciência transindividual da relevância das discussões em torno da questão da formação da nacionalidade, da busca de identidade, bem como das ideais de civilização e progresso que estavam na pauta das preocupações dos intelectuais brasileiros e dos governos instituídos com a proclamação da República. Em certa medida, era perceptível o reconhecimento de obrigações associativas pertinentes a esse contexto. Nessa perspectiva, era necessário olhar a sociedade brasileira como quem deseja entendê-la, desvendar as suas peculiaridades e buscar explicações para uma

\footnotetext{
4 Jornal de abrangência regional que circulou entre 1897 a 1943 e onde João Gumes, além de jornalista, era proprietário e redator chefe.
}

realidade que se mostrava cheia de limitações, face aos modelos externos de progresso. As teorias científicas em voga na virada do século XIX para o século XX adotavam análises deterministas e evolucionistas que atribuíam à ação do tempo e aos fatores étnicos e climáticos a responsabilidade no desenvolvimento ou atraso dos lugares e dos povos. Era como se o progresso fosse o único destino possível a todos os povos e, neste caso, o Brasil estaria desacreditado; estas teorias contribuíram para que se desenvolvesse uma ideia de atraso, um certo pessimismo e fatalismo em relação ao Brasil, como quem está fadado a não dar certo dentro do modelo estabelecido. "Fatalismo diante de algo que não poderia ser evitado e pessimismo com relação às possibilidades do Brasil diante do progresso da humanidade" (NAXARA, 1998, p. 41). Era como se existisse o Brasil enquanto Estado, mas não enquanto nação e segundo intelectuais como Sílvio Romero e Euclides da Cunha que buscaram interpretar o Brasil da época, a nação brasileira só passaria a existir quando se desse a formação de um grupo étnico homogêneo para, enfim, constituir-se a identidade do brasileiro e, portanto, da nacionalidade e da nação.

Estas teorias abriam debates calorosos, carregados de contradições que desembocaram em explicações dos diferentes níveis de desenvolvimento dos povos, justificando a superioridade de uns sobre o atraso dos outros, como uma dicotomia civilização-barbárie. E o Brasil, numa classificação bem geral, alinhava-se à barbárie pelos descompassos aqui vivenciados: de um lado, uma elite "civilizada", de outro, uma pobreza alarmante, uma população miserável, "atrasada"; ou, litoral desenvolvido versus interior atrasado; ou, população das cidades identificadas com o progresso e populações rurais identificadas com a estagnação. Assim, buscava-se explicar o que atrapalhava o desenvolvimento e o que poderia ser "possibilidade" na mudança do processo histórico rumo ao progresso (NAXARA, 1998, p. 42).

Gumes, ao contrário, numa construção própria de quem fala de "dentro" do seu espaço, de quem se 
identifica ou acredita nas potencialidades daquele espaço, coloca em suas tramas as particularidades da cultura sertaneja, seus hábitos, costumes e valores. Coloca-se como quem quer valorizar e enaltecer a sua região. Aos estereótipos de preguiçosos e matutos, Gumes contrapõe sertanejos aptos para o trabalho e muito honestos. Eximia o sertanejo de qualquer culpa, denunciando a ausência de investimentos públicos na melhoria das condições da região e demonstrava-se aflito por não existirem pessoas interessadas em defender os interesses dos sertanejos, conforme escreve na apresentação do seu romance, Os Analfabetos (1928):

A não ser o jurisconsulto, professor ou algum membro do clero, cada qual no domínio do seu ministério, quem se preocupa com a bela arte de escrever? Quem se dedica a uma cerrada campanha em prol dos nossos interesses agrícolas; em demonstrar as vantagens que oferece a nossa terra tão opulenta em recursos naturais; quem procura tornar conhecida a índole do nosso homem do campo, honesto, pacífico, laborioso? Quem procura combater a má idéia que fazem, nos centros cultos, do nosso pobre povo, que é tão caluniado, invetivado e mal visto lá por fora? (GUMES, 1928, p. 1).

E continua em defesa desta região, querendo desfazer as imagens deturpadas que vigoram em outras partes do país, contrapondo uma realidade cheia de possibilidades e por isso, escreve no prefácio, à primeira página:

As secas, o banditismo e a vagabundagem são os atributos que nos emprestam mesmo na Capital do nosso Estado; são, dizem por lá, as causas do nosso atraso, da nossa pobreza tão falada, do nosso imerecimento. Reduzidos a ilotas desprezíveis, considerado o alto sertão uma região inóspita onde o ádvena corre o perigo de ser assassinado nas estradas pelos selvagens sertanejos, ninguém, que para isso tenham autoridade, levanta a voz em nossa defesa. 0 que mais admira é que sertanejos malévolos que aqui residiram, que aqui nasceram e foram criados chegam a confirmar, senão que somos jagunços, ladrões ou vagabundos, ao menos que o nosso território é safaro, que passamos anos e anos sob a inclemente causticante solina sem o refrigério de uma chuva; que o nosso povo é preguiçoso, indolente e degenerado (GUMES, 1928, p. 1).
Como João Gumes era visto entre os críticos e estudiosos da literatura baiana? Aparecem poucas referências a ele, sendo citado entre os regionalistas "menos rígidos" que valorizam mais o humano em detrimento de outros aspectos pitorescos ou aparece no rol dos regionalistas que ficaram limitados a uma abrangência local, por falta de incentivos e de iniciativas editoriais que dessem vulto às obras dos autores citados (REIS, 2004, p. 27).

A utilização da denominação Alto Sertão Baiano marca toda a sua produção e isso nos reporta à noção de espaço, articulada à noção de discurso da seguinte forma:

Os discursos não se enunciam, a partir de um espaço objetivamente determinado do exterior, são eles próprios que inscrevem seus espaços, que os produzem e os pressupõem para os legitimarem. 0 discurso regionalista não é emitido, a partir de uma região objetivamente exterior a si, é na sua própria locução que esta região é encenada, produzida e pressuposta. (ALBUQUERQUE JUNIOR, 2009, p. 34).

0 nosso autor escreveu numa época em que o seu espaço circunscrevia-se a uma delimitação mais ampla conhecida como Norte, em oposição ao Sul do Brasil, ou litoral em oposição ao interior. Não aparece em Gumes a ideia imagética e discursiva que começa a se formar a partir da segunda década do século XX e que se cristaliza com o nome de Nordeste.

0 discurso regionalista de Gumes inscreve-se num período posterior ao declínio do Romantismo e do Realismo na literatura brasileira. Nos primeiros anos do século $X X$, seu discurso romanesco contém a seiva de uma tendência nacionalista em voga, que não é abandonada, mesmo porque suas descrições são apologéticas das peculiaridades do Sertão, tanto do ponto de vista geográfico quanto cultural.

Por esta época, a sociedade brasileira dos engajados nas questões sociais e políticas dividia-se entre os conservadores monarquistas e os republicanos 
progressistas. Gumes, parcimonioso e conservador em muitas questões, nesse caso especificamente demonstrou afinidade com o segundo grupo, uma vez que atacava a escravidão e acreditava no aperfeiçoamento da democracia a partir da nova forma de governo. Diante dos desdobramentos desses embates ideológicos, a corrente ufanista aparece como uma vertente que defendia uma nacionalidade ancorada nas condições naturais da terra, numa mãe natureza prodigiosa e bem aproveitada pelo homem brasileiro, otimista quanto a um futuro promissor. ${ }^{5}$ Gumes assume este ponto de vista em relação à sua região e, assim, produz os seus romances descrevendo com riqueza de detalhes os encantos da natureza ou as vicissitudes de um meio adverso. Acredita nas muitas possibilidades de exploração da terra e no retorno financeiro garantido, a partir de um trabalho contínuo e disciplinado. É com estes argumentos que desenvolve a sua ação obstinada de combate à emigração dos sertanejos:

Ah! Se todos os moços, despindo-se dos preconceitos e receios que os afugentam dos rudes trabalhos do campo, experimentassem as doçuras dessa vida inocente, pacífica e proveitosa; se considerassem que um grão de cereal se reproduz milagrosamente em milhares e que a terra, essa mãe dadivosa, apenas aguarda o carinhoso beijo do trabalho metódico, perseverante e honesto, para se desatar em opulentos recursos, em riquezas compensadoras que nos trarão a felicidade e 0 sossego; se avaliassem que encanto perene e inefável, que alegria sã e permanente nos reservam as fainas rurais - dedicar-se-iam com afã à vida agrícola. Diziam os nossos antepassados: "Planta e cria e terás alegria”. Não há adágio que mais contenha critério e justeza. (GUMES, 1917, p. 74).

0 processo crescente de emigração sertaneja para outras paragens, especialmente São Paulo, era abordado por Gumes na tentativa de esclarecer os prejuízos que isto acarretaria tanto para famílias inteiras, afetando a essência do ser humano e as bases da sociedade, como para a região que se despovoava e se ressentia da falta de mão de obra. No primeiro caso, é como se houvesse o "desenraizamento cultu-

\footnotetext{
5 Este tema é abordado por OLIVEIRA, Lucia Lippi (1997).
}

ral" das pessoas, para utilizar a expressão citada por Ecléa Bosi (2006, p. 17); 6 o emigrante deixa as suas raízes pra trás e vai perdendo-as cada vez mais ao distanciar-se da sua paisagem natal, dos seus costumes, forma de vestir, modos de falar, suas festas, todos os seus rituais enfim. Estas raízes são fincadas na dinâmica das suas relações sociais e em uma participação na coletividade. Ali, ele é conhecido e reconhecido em sua dignidade. Encontrar uma vida plena fora da sua realidade, é um desafio para quem antes, precisa sentir-se "enraizado", afinado com as suas origens, para assim, sentir-se feliz. E, no segundo caso, os prejuízos para a região, fazem aparecer escassez de alimentos e anos de crises para seus habitantes.

Está na pauta das discussões de Gumes, o papel do trabalho como elemento importante na rearrumação das tendências da mão de obra pós-abolição da escravatura. Este era o tema mais presente na sociedade, uma vez que vivíamos a substituição do trabalho escravo para o trabalho livre e, notícias de rebeliões ou outras formas de resistência escrava do período anterior à abolição traziam um clima de desconfiança em relação aos libertos; de outro lado intensificava-se a busca de imigrantes vistos como "o tipo ideal" para suprir as necessidades do trabalho, em prejuízo ao aproveitamento da população livre pobre, mestiços e ex-escravos, vistos com desconfiança e temor. Neste sentido, Gumes, concatenado com as ideias em voga no país, procurava num movimento inverso, incentivar os meios para inserção desta mão de obra pobre nas condições de trabalho que a sua região oferecia, no caso a agricultura e a criação de gado ${ }^{7}$. Era preciso acreditar no homem apto para o trabalho, um trabalho

\footnotetext{
6 Esta autora, citando Simone Weil, diz que "o enraizamento é talvez a necessidade mais importante e mais desconhecida da alma humana e uma das mais difíceis de definir"; é um direito humano que muitas vezes é esquecido (BOSI, 2006).

7 Um dado importante é considerar que na região alto-sertaneja, que não dispunha de cultivos em grande escala para exportação (como em outras regiões do país), não há registros de vinda de imigrantes em grande número; alguns poucos que para se transferiram para Caetité e região era com objetivos bem específicos. Segundo Naxara (1998, p. 70), houve um movimento de revalorização do trabalhador nacional brasileiro depois da $1^{\text {a }}$ Guerra Mundial, principalmente em relação às populações pobres habitantes das cidades.
} 
que o dignificasse, abrisse caminho para a cidadania e para a sua melhoria econômica e social. A pobreza e a falta de alimentos não são causadas pela seca da região, mas pela falta de se trabalhar e acreditar na terra (GUMES, 1917, p. 78). Reiteradas vezes, em seus romances, aponta a agricultura como o caminho para a prosperidade do país, da qual advêm "hábitos e virtudes que tornam um povo nobre, digno, respeitável, unido, em resumo, civilizado" (GUMES, 1917, p. 96).

Na sua apologia ao trabalho, Gumes critica a febre dos aventureiros que buscavam Brejinho das Ametistas $^{8}$ acreditando no enriquecimento fácil e rápido. Para ele, apesar de no Brasil “ainda não estar constituída uma raça definida, pois entre nós os elementos étnicos são diversos e diferentes entre si, não devemos atribuir esse modo de ver e agir a propensões inatas. 0 que podemos admitir, fora dos hábitos adquiridos, é a sugestão do meio" (GUMES, 1917, p. 78).

\section{5 É POSSIVEL NOTICIAR PRINCÍPIOS JURÍDICOS COM BASE NO FATO HISTÓRICO INVESTIGADO A PARTIR DE FONTES LITERÁRIAS?}

Conforme exposto, cabe ao historiador a tentativa de explicação de dada realidade, com base em uma verdade ou na máxima aproximação possível da mesma. A Literatura, a partir dessas reflexões, posicionou-se como recurso privilegiado para o esclarecimento de fatos históricos, muitos deles de extrema utilidade ao Direito.

Neste estudo, vale realizar a busca do fato histórico, com fincas à verificação do possível delineamento de uma personificação política para o evidenciar de princípios jurídicos de uma conjuntura.

8 Localidade rica em minerais e pedras preciosas que integra o território do município de Caetité, hoje é distrito, uma das suas divisões administrativas.
Concluindo esta análise, pode-se dizer que o nosso autor, ao contrário de outros escritores brasileiros da mesma época, não era pessimista em relação às potencialidades do sertanejo e às possibilidades econômicas do sertão, e não corroborou para disseminação dos estereótipos já citados anteriormente, no entanto, desta última citação, depreende-se que Gumes considerava outros valores importantes para que houvesse um desenvolvimento do sertão sem haver a anulação das suas raízes; deveria ser um progresso "conservador", mantendo os "hábitos patriarcais" e um certo receio em abraçar costumes diferentes; sertanejos deveriam evoluir "cautelosamente", fugindo das artimanhas dos hábitos não saudáveis e que tão rapidamente são adotados pelas novas gerações. Esta sua fala de escritor traduz evidentemente a sua visão de mundo e a sua expressividade sobre o Alto Sertão Baiano, e traz contribuições relevantes aos estudos sobre a sociedade sertaneja.

Se a comunidade contemporânea da obra de Gumes era personificada e, de fato, acredita-se que, com todas as desigualdades e crises de identidade havia reconhecimento da personificação política à época, o fato histórico pode servir como fonte de exploração dos conteúdos e expressões de princípios jurídicos que vigiam àquele tempo ou que eram clamados pelos cidadãos.

Se, muitas vezes, a teoria do Direito como Integridade é atacada por ter sido elaborada em contexto político-estatal bastante diferente do brasileiro, parece muito nos servir no que tange à contribuição do fundamento da obrigação associativa que, por sua vez, embasa o poder de coerção dos princípios jurídicos. 
Na tentativa de cumprir o objetivo e realizar reflexões simplistas que representam muito mais um cogitar preparatório a um futuro estudo, cumpre destacar da análise da obra realizada, quais fatos históricos abstraídos da Literatura poderiam insinuar anúncios de princípios que surgiam ou que, muito em breve, viriam a firmar-se.

0 processo crescente de emigração sertaneja para outras paragens, especialmente São Paulo, era descrito por Gumes. 0 desenvolvimento nacional uniforme nos moldes almejados pela Constituição (BRASIL, 1988) era ainda menos tangível. Demonstrou-se que eram presentes discussões, angústias e contradições em busca de uma identidade nacional. Isso sugere que, a despeito da consciência da condição de nação, era flagrante a visão pejorativa que regiões mais prósperas tinham do Alto Sertão Baiano, que, por sua vez, clamava por políticas públicas que visassem à redução das desigualdades regionais no Brasil. As constituições posteriores encamparam o princípio da promoção do desenvolvimento nacional e da redução das desigualdades regionais. $\mathrm{E}$ a atual Constituição (BRASIL, 1988) preconiza esses conteúdos normativos como um de seus objetivos.

Lado outro, ainda estavam bastante visíveis as repercussões do longo período de escravidão no Brasil. Àquela circunstância, já se identificavam grupos políticos que atacavam a escravidão e acreditavam no aperfeiçoamento da democracia a partir da nova forma de governo. É defensável que a semente do Estado Democrático de Direito já germinava, uma vez que era reconhecido pela comunidade personificada como anseio transcendente à consciência de seus membros considerados isoladamente.

Gumes destacou ainda, as possibilidades de exploração da terra e no retorno financeiro garantido, a partir de um trabalho contínuo e disciplinado. Já era iminente a força que ganharia o princípio da função social da propriedade 9 . Afinal, o crescimento desor-

9 Constituição da República (BRASIL, 1988). “Art. $5^{\circ}$ Todos são iguais peran- denado da sociedade e o status de valor absoluto da propriedade são evidentes na Literatura apreciada, demonstrando a incompatibilidade de tais concepções com anseios e valores sociais existentes já àquele tempo, de consideração do espaço à pessoa, para exercício de sua dignidade.

Também eram frequentes as abordagens do papel do trabalho como elemento importante na rearrumação das tendências da mão de obra pós-abolição da escravatura. Gumes era defensor do incentivo à inserção da mão de obra pobre nas condições de trabalho que a sua região oferecia, pondo em realce a consciência comunitária da imperiosidade da valorização do trabalho humano e da fixação do homem à terra e às suas raízes.

Ainda merece relevo, a ideia de Gumes em que parece retratar uma visão maior que a do próprio autor, de que o desenvolvimento do sertão deveria ocorrer de forma conservadora, preservando, até mesmo, "hábitos patriarcais". Não é à toa que a estrutura familiar pautada no patriarcalismo ainda teve lugar por décadas seguintes.

Como dito anteriormente, não é intenção do trabalho ocupar-se do estudo do fato histórico evidente na Literatura para identificar e preencher, com segurança, conteúdos deônticos de princípios jurídicos vigentes àquele tempo e contexto. As brevíssimas reflexões servem, somente, para anunciar fase futura da pesquisa, mas, sobretudo, para reconhecer legitimidade da Literatura como fonte viável à pesquisa histórico-jurídica, que é, por sua vez, essencial ao tracejo do panorama jurídico de determinada época, haja vista que ele depende dos anseios da sociedade em um dado contexto, demonstrados pelo fato histórico, para evidenciar seus princípios.

te a lei, sem distinção de qualquer natureza, garantindo-se aos brasileiros e aos estrangeiros residentes no País a inviolabilidade do direito à vida, à liberdade, à igualdade, à segurança e à propriedade, nos termos seguintes: XXIII - a propriedade atenderá a sua função social.”. 


\section{CONSIDERACÕ̃ES FINAIS}

Adotada a concepção interpretativa do Direito como Integridade, a comunidade personificada corresponde ao modelo da comunidade de princípios. Os princípios, por sua vez, dependem das obrigações reciprocamente consideradas na comunidade personificada. Por essa razão, a comunidade de princípios é aberta à realidade social, além de ser plural, na medida em que é na transcendência da pluralidade que a comunidade se personifica.

Dessa maneira, o Direito não prescinde da experiência histórico-social. Essa evidencia a consciência da comunidade personificada, ou seja, sua moral política. E é a partir dessa consciência, que depende do contexto e da atitude interpretativa, que se forma a comunidade de princípios. Os princípios jurídicos, portanto, são evidentes a partir do panorama jurídico da comunidade personificada.

Trabalhar esses princípios a partir do fato histórico parece viável, com recurso à Literatura. Essa visão

\section{REFERÊNCIAS}

ALBUQUERQUE JUNIOR, Durval Muniz de. A invenção do nordeste e outras artes. São Paulo: Cortez, 2009.

BAKHTIN, Mikhail. Estética da criação verbal. São Paulo: Martins Fontes, 1992.

BARDIN, Laurence. Análise de conteúdo. Lisboa: Edições 70, 1977.

BENJAMIN, Walter. Sobre o Conceito de História. In: Magia e Técnica, Arte e Política: obras escolhidas. v. I. São Paulo: Brasiliense, 1994.

BOSI, Ecléa. Cultura e desenraizamento. In: BOSI, Alfredo (Org.). Cultura Brasileira - temas e situações. São Paulo: Ática, 2006. contribui para a ampliação das fontes, que pode ser um artifício útil contra as mazelas da historiografia oficial. A Literatura pode revelar um estado de coisas e seu processo consolidado de mudança. Em razão de sua capacidade de espelhar a realidade de uma época e, paralelamente, de libertar o escritor das amarras de seu tempo, permite o enfrentamento e a descrição de panoramas mais fidedignos. No que respeita ao romance, sua contribuição é significativa por comportar espaço à diversidade, diferença e heterologia. Conclui-se, assim, pela existência de metodologia apta a assegurar a utilidade e validade da relação Direito, História e Literatura à pesquisa histórico-jurídica.

Então, em outra oportunidade, essas constatações podem servir de premissas para a proposta de abstrair princípios jurídicos em diferentes épocas históricas, mediante estudo de contextos diversos, tomando por fonte a Literatura.

BRASIL. Constituição da República Federativa do Brasil de 1988. Disponível em: <http://www.planalto.gov.br/ccivil_03/Constituicao/Constituiçao.htm>. Acesso em: 18 jan. 2012.

BURKE, Peter. 0 que é História Cultural? Rio de Janeiro: Zahar, 2005

CANDIDO, Antonio. Literatura e Sociedade. Estudos de Teoria e História Literária. 10 ed. Rio de Janeiro: Ouro sobre Azul, 2008.

CHALHOUB, Sidney; PEREIRA, Leonardo Affonso de M. (orgs). A História Contada: capítulos de História Social da Literatura no Brasil. Rio de Janeiro: Nova Fronteira, 1998. 
CHARTIER, Roger. A História Cultural: entre práticas e representações. Rio de Janeiro: Difel, 1988.

\section{CHARTIER, Roger. A História ou a leitura do tempo.} Belo Horizonte: Autêntica, 2009.

DANNER, Mário Fernando Passos. Graciliano Ramos e a crônica - Uma vida em três séries. In: CHALHOUB, Sidney; NEVES, Margarida de Souza; PEREIRA, Leonardo Affonso de Miranda (Orgs.). História em coisas miúdas. Capítulos de História Social da crônica no Brasil. Campinas: Editora da Unicamp, 2005.

DWORKIN, Ronald. 0 império do direito. Trad. Jefferson Luiz Camargo. São Paulo: Martins Fontes, 2003.

FERREIRA, Antonio Celso. A fonte fecunda. In: PINSKY, Carla Bassanezi; DE LUCA, Tânia Regina. 0 historiador e suas fontes. São Paulo: Contexto, 2009.

FIORIN, José Luiz. Introdução ao pensamento de Bakhtin. São Paulo: Ática, 2008.

GUMES, João. Vida Campestre. Caetité: A Penna, 06 set. 1917.

GUMES, João. Os Analphabetos. Salvador: Escola Typographica Salesiana, 1928.

GUMES, João. Pelo Sertão. Caetité: A Penna, 11 jul. 1913/27 mar. 1914.

JORNAL A PENNA. Caetité, 1897-1930.

LE GOFF, Jacques. 0 Imaginário Medieval. Lisboa: Estampa, 1994.

LE GOFF, Jacques; NORA, Pierre. Historia: novos problemas; novas abordagens; novos objetos. Rio de Janeiro: Francisco Alves, 1976.
LUKÁCS, Georg. 0 romance como epopéia burguesa. Tomo II Santo André-SP: Estudos e Edições Ad Hominem, 1999.

NAXARA, Márcia Regina Capelari. Estrangeiro em sua própria terra - representações do brasileiro 1870/1920. São Paulo: Anna Blume, 1998.

NEVES, Erivaldo Fagundes. Uma comunidade sertaneja: Da sesmaria ao minifúndio (Um estudo de História Regional e Local). Salvador: Editora da UFBA, 1998.

OLIVEIRA, Lucia Lippi. Questão Nacional na Primeira República. In: LORENZO, Helena Carvalho de; COSTA, Wilma Perez da. A década de $\mathbf{1 9 2 0}$ e as origens do Brasil Moderno. São Paulo: UNESP, 1997.

REIS, Maria da Conceição Souza. O Sampauleiro: romance de João Gumes. 2004. Tese (Doutorado) - Universidade Federal da Bahia, Salvador, 2004.

RICHARDSON, Roberto Jarry. Pesquisa social: Métodos e Técnicas. São Paulo: Atlas, 1999.

SEVCENKO, Nicolau. Literatura como missão: tensões sociais e criação cultural na Primeira República. São Paulo: Brasiliense, 1999.

THOMPSON, E. P. O Termo Ausente: Experiência. In: A Miséria da Teoria ou um planetário de erros: uma crítica ao pensamento de Althusser. Rio de Janeiro: Zahar Editores, 1981.

WILLIAMS, Raymond. Conceitos Básicos e Teoria Cultural. In: WILLIAMS, Raymond. Marxismo e Literatura. Rio de Janeiro: Zahar Editores, 1979. 
1 Doutorando e mestre em Direito Privado pelo Programa de Pós-Graduação da Pontifícia Universidade Católica de Minas Gerais. Professor Efetivo em Dedicação Exclusiva e Membro do Colegiado do Curso de Direito da Universidade Federal de Ouro Preto. portonogueira@gmail.com

2 Doutoranda em História Social pela Universidade do Estado de São Paulo - USP. Mestre em História Social pela Pontifícia Universidade Católica de São Paulo - PUC/SP. Professora auxiliar da Universidade Estadual da Bahia. mluciaporto@yahoo.com.br 